\title{
A impressão 3D como suporte para o ensino das artes para deficientes visuais
}

\author{
3D printing as support for arts education for the visually impaired \\ - Dra. Ana Beatriz Linardi \\ FACAMP - Faculdades de Campinas, Brasil \\ anabeatriz.linardi@gmail.com \\ - Dr. Fernando da Silva Ramos \\ FACAMP - Faculdades de Campinas, Brasil \\ fernandala@gmail.com
}

\begin{abstract}
This article discusses some methodologies in art education in schools and educational activities in museums. It focuses on accessibility and in the visually impaired rights to access and improve the experiences and repertoire in artistic languages, recognizing the use of new technologies in the field of digital manufacturing as valuable resources for the production of teaching materials with the use of cheaper and accessible technology, which expands the access to cultural institutions and education. Considering that most of the museums art works are not to be touched, 3D printing reproductions in durable low cost plastic present as an alternative for tactile experience. In addition, the photogrammetric 3D scanning process and digital editing allow for the creation of isolated parts and materials originated from the art piece, broadening the pedagogical possibilities of art educators. The production of didactic material for arts teaching, with the use of 3D printed copies (edited or not) originated from 3D scans, may help revealing a more subtle and sophisticated aspect of artistic narrative to the public and the visually impaired.
\end{abstract}

Keywords: Education, Art, 3D Scan, 3D Printing

\section{Introdução}

A preocupação com a acessibilidade trouxe à tona um grande empenho em tornar acessível, especialmente aos deficientes visuais e pessoas com a visão reduzida, o campo das artes, especialmente as artes visuais, por se constituir elas o maior desafio em relação ao que a própria definição já traduz: o visual.

Partindo-se da premissa de que o conhecimento e vivência da experiência artística provocados pelo contato com o patrimônio cultural, são direitos universais, muito se tem refletido e debatido sobre as maneiras de apresentá-los aos deficientes visuais

A primeira e intuitiva ação que vem nessa direção, conduz o visual em direção ao tátil. Quadros táteis ou miniaturização dos objetos artísticos procuram aproximar desse modo sensorial, algo que por si não é vivenciado pelo tato, o que já levanta uma série de questões.

No percurso entre o visual e o tátil, quando se fala em tornar acessível uma obra de arte para um deficiente visual, há um grande caminho a ser percorrido.

A simples miniaturização ou transformação em 3D de um quadro ou escultura, não possibilita ao deficiente visual o propósito final de uma obra: a fruição - ou melhor dizendo, sua experiência. Pode trazer a ele os elementos que compõe o quadro - o tema - mas não a experiência artística.

Quando contemplamos uma obra de arte, acionamos todo um repertório visual ou uma gramática que permite decifrar esse código e apreender uma obra como obra de arte.

O deficiente que nunca enxergou, e que por isso não teve acesso à gramática da representação artística, não possui de imediato, elementos de decifração desse código.

Dessa forma, oferecer ao cego a possibilidade de tatear uma obra que foi transformada por um vidente em algo chamado tátil, pode não fazer sentido algum como arte. O sentido daquela experiência acaba se constituindo primordialmente através daquilo que é dado através de outros recursos, como um texto ou narração.

Se tomarmos como exemplo uma natureza morta, cuja composição é formada por objetos que o cego tateia cotidianamente em sua casa, tais como uma mesa com copos, jarro e uvas, por exemplo, de que maneira um jarro, copos e uvas se constituirão, para ele, em obra artística? Ou no caso de uma pintura abstrata, cujo movimento de linhas e massas de cores se apresentará a ele através do tato como uma massa disforme, e uma descrição de sua constituição, produzida por um vidente.

Por outro lado, a experiência artística também não é 
plenamente acessível ao público em geral, visto que nosso sistema de ensino básico relega a último plano o ensino das artes e, muitas vezes o rebaixa como se fosse apenas a oportunidade de enfeitar uma escola em ocasiões festivas.

A inacessibilidade da arte não se restringe aos portadores de deficiência visual mas, ao público em geral.

Desta maneira, entendemos que o acesso dos deficientes às artes visuais, levanta questões no âmbito do ensino, que são questões gerais. $\mathrm{O}$ desafio porém é maior por não podermos contar primeiramente com as habilidades visuais.

Por outro lado entendemos que os recursos utilizados para cumprimento do objetivo de tornar uma obra de arte acessível ao deficiente visual, traz um processo novo de ensino e aprendizado que poderá ser utilizado igualmente pelo público vidente.

Parte-se do princípio de que a apresentação de uma obra de arte é apenas parte da tarefa, e que seu significado se completa quando procura-se ensinar sobre arte: o que é arte e como se apresenta.

Com o propósito de avaliar a validade destas premissas, escolhemos a escultura Sóror Dolorosa de autoria de Victor Brecheret (1921) inspirada no Livro de horas de Sóror Dolorosa (1920) de Guilherme de Almeida, que integrou a exposição do artista na Semana de Arte Moderna de 1922, hoje hospedada no Museu Casa Guilherme de Almeida, em São Paulo. Como experiência de uma ação pedagógica no âmbito artístico, propomos, através do processo de Impressão 3D, realizar réplicas dessa escultura, que tem grande importância no acervo artístico de obras brasileiras, de forma que resulte em um produto articulado, com partes removíveis, para ensinar sobre o processo artístico da representação, do gesto expressivo, estilização e interpretação da obra, visando em princípio as particularidades dos deficientes visuais e, por extensão, o público em geral. Uma vez impressas as partes, a réplica e a produção dos demais materiais complementares, o Museu oferecerá ao público deficiente visual ou não, oficinas que colocarão em prática a metodologia, para que se possa avaliar a aproximação da obra ao público através desses recursos metodológicos.

Sóror Dolorosa de Brecheret para Deficientes Visuais como Paradigma de uma Metodologia de Ensino das Artes Visuais

A escultura: Sóror Dolorosa é uma escultura em bronze composta de duas figuras humanas ligadas que se entreolham, no alinhamento dos eixos vertical e horizontal. A figura feminina contempla o rosto do amado e se debruça sobre ele. Não há outros elementos do corpo humano além de suas cabeças. A modelagem das figuras revela o gesto e as marcas das mãos do artista, e se concentra em representar rostos petrificados numa expressão de dor e sofrimento.

Para quem enxerga, a contemplação da obra claramente revela uma relação amorosa e a dor da perda daquela que se debruça sobre o corpo sem vida do amado, de forma que o peso da dor é completado pelo material usado na obra. $\bigcirc$ bronze endurece as faces e demonstra a rigidez dos músculos que, impedidos de soltar livremente a expressão de dor, são contidos na introspeção. Dessa forma as duas figuras se fecham na representação da dor e do luto.

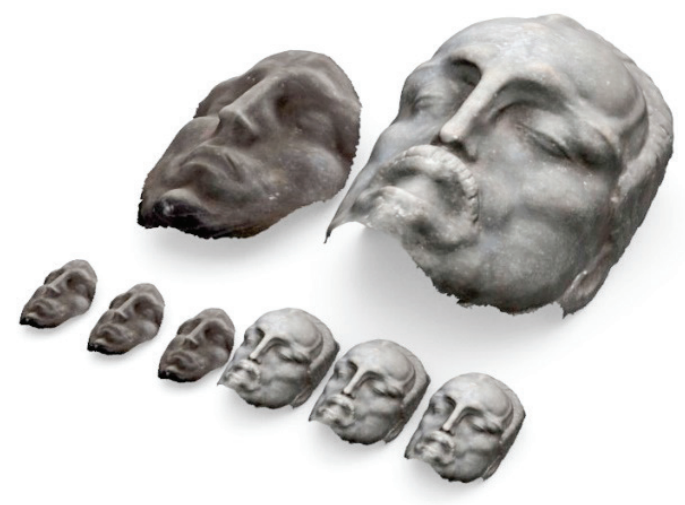

Figura 1: Vista do processo de fotogrametria.

Para quem não enxerga, como fruir desse movimento de dor e olhares impressos na matéria rígida pelo artista, de forma que o tato consiga dar conta desse jogo de expressão/matéria/ forma que, concebidos para serem vistos e assim sentidos, tem sua principal porta de acesso, a visão, indisponível. Essa questão, de compreensão da obra de Brecheret está no centro da questão da fruição de obras de arte visuais pelos deficientes visuais. A Sóror nos aponta uma possibilidade de aplicar uma metodologia através da impressão 3D, que poderá, a partir de seus resultados, ampliar as possibilidades de utilização desses recursos tecnológicos para outras obras artísticas, inclusive as de grandes dimensões.

Como construir caminhos outros que permitam àqueles que não enxergam a fruição da obra, a compreensão da intenção do artista, o acesso à poética das artes?

O caminho então não se restringe a apresentar a obra, como fenômeno localizado na história da arte, para ser apenas tocada mas, trazer com ela uma gama de conceitos que situe o deficiente visual diante das obras artísticas, estabelecendo conexões e referenciais, para que ele possa ser capaz de construir sentidos sobre a obra que ele irá conhecer.

Recursos consolidados tais como a audiodescrição ou a narração, reduzidos a legendas da experiência tátil, não são suficientes a fornecer ao deficiente visual, subsídios para uma livre interpretação da obra, nem colaboram na aquisição de um repertório de referências que o usuário utilizará para além do conhecimento dessa obra em particular, e futuramente de outras.

A adoção das tecnologias de escaneamento por fotogrametria e impressão 3D, amplia o ferramental de descrição do arte educador, possibilitando partir de um modelo digital extraído a partir da própria obra, para atuar sobre ela na criação de um referencial físico que vá além de sua cópia 
fiel, de modo a ampliar as possibilidades narrativas; podese assim decupá-las, modificar sua escala e isolar elementos como forma de complementar o ensino sobre elas. Não se trata portanto de minituralizá-las apenas (no caso de obras em grande escala), ou reproduzi-las para serem tocadas, mas tirar proveito das potencialidades que o escaneamento e edição digitais para fins de impressão 3D possibilitam para as metodologias de arte educação. Pensamos assim amplamente em um processo global de educação para as artes e não apenas fornecer informações sobre determinadas obras. Por isso, falamos em metodologia de ensino e não somente em replicar os objetos artísticos.

Sendo assim, decupamos a fruição artística em etapas que são necessárias abordar e que espera-se obter através de réplicas tridimensionais inicialmente da obra Sóror Dolorosa de Brecheret, articuladas, com partes removíveis, para que se ensine sobre arte a partir dos seguintes princípios:

\section{A Representação do Rosto Humano e Suas Expressões} Dado que a Sóror de Brecheret é formada por duas figuras humanas representadas pelos seus rostos, podemos criar uma gramática de reconhecimento de expressões e significações a partir da representação da figura humana nas artes.

Imprimir os rostos dos dois personagens separadamente para que sejam individualmente explorados. Isso por si só já nos dá referenciais importantes sobre as respostas do tato em relação às representações de objetos conhecidos, no caso, o rosto humano.

Quais os limites de escala para que se possa reconhecer expressões faciais impressas em matéria. $O$ tato é suficiente para informar as expressões representadas, ou essa é uma qualidade a ser descrita? Quais os limites entre o que é naturalmente reconhecível através do tato e o que pode ser aprendido utilizando esse sentido?

Essas questões serão verificadas durante o contato dos deficientes visuais com a obra.

Nesse sentido as obras de arte fornecem um rico objeto de pesquisa cujos resultados podem ser aplicados em outros materiais impressos tridimensionalmente. Outra questão que a metodologia aborda é: pode-se criar uma gramática de leitura de formas, semelhante ao papel que o Braille tem na linguagem escrita?

\section{A Junção de Elementos no que se Constitui uma Composição Artística}

Um dos caminhos para compreensão de como os elementos justapostos compõem uma obra de arte, é a apresentação deles separadamente. Talvez seja mais difícil para alguns compreenderem a composição da obra de Brecheret pela justaposição de duas cabeças, sem outros elementos de seus corpos que justifiquem essa junção. Mostrando separadamente os elementos e como eles juntos, formam a composição, cria-se um conceito mais claro da representação estilizada, que enfatiza, no caso, a expressão da dor através

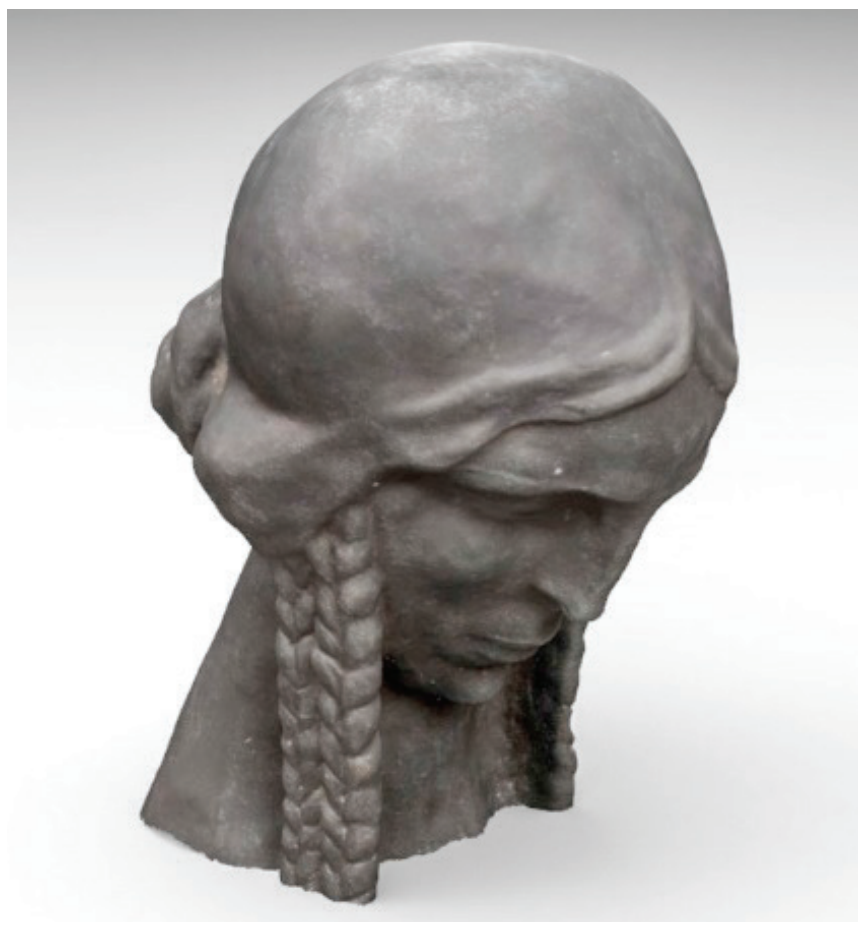

Figura 2: isolamento da cabeça em perspectiva 3D.

dos rostos, a intenção do artista de concentrar toda uma gama de significantes em uma forma sintética, constituindo-se apenas por esses elementos, sem a necessidade de representar a figura humana em sua totalidade para representar duas personagens em dada ação expressiva.

\section{A Estilização Como Recurso Expressivo}

Brecheret não era um artista realista na representação das figuras humanas em sua obra. Nessa em especial, as relações de proporção dos elementos do rosto humano são modificados. Os rostos são alongados e traduzem os traços próprios da estilização do artista. Entender esse recurso expressivo próprio da linguagem visual é necessário para que as "deformações" sejam compreendidas como recursos estilísticos e não deformações do referencial real. Esse é um problema que a maioria do público leigo vidente tem diante das obras de arte que se afastam do real, em termos formais. O senso comum entende como boa obra ou bom desenho, a reprodução fotográfica do real e, dessa forma muitas vezes se afasta das obras modernas, cuja deformação do real é elemento expressivo essencial. Esse conceito de alteração das formas em relação ao real pode ser dado através da impressão dos rostos da Sóror e suas modificações em relação a um suposto rosto em proporções reais. Dessa forma o deficiente visual entroniza o conceito de estilização e o público vidente entende como recurso expressivo.

\section{A Soma das Partes que Compõem a Obra}

Blocos justapostos, soma de partes, a estrutura material de uma escultura é tão importante quanto aquilo que ela representa. Quais os processos de construção material dessa 
obra? Isso pode ser demonstrado em partes que se deslocam e se agrupam.

\section{O Gesto Artístico da Modelagem que Antecedeu a Fundição da Obra no Bronze}

Enfatizar, aumentar e imprimir as impressões das mãos do artista na obra, é praticamente como ver seu processo de produção. $\mathrm{O}$ deficiente visual e o público não iniciado nas artes, tem ideia do que é uma modelagem? Que foi fruto de um gesto artístico sobre uma matéria concebendo a forma e dotando-a de significado? A impressão de detalhes da obra em escala ampliada pode auxiliar nessa questão.

\section{Compartilhamento Digital dos Resultados}

Além da reprodução da obra para oficinas específicas em museus, os arquivos digitais podem ser disponibilizados para fins educacionais e culturais diversos, através de acervos digitais públicos, ampliando assim o acesso à obra para além dos limites do museu que a abriga. No caso da obra em questão - que é importante item do acervo artístico brasileiro - o material produzido poderá ser utilizado por exemplo, como material didático complementar no estudo da semana de 22, por diversas disciplinas escolares que abordarem o tema, criando uma transversalidade curricular, que é almejada pelos parâmetros educacionais.

A expectativa é que, de posse dos arquivos digitais, toda e qualquer instituição brasileira ou não, que se interessar em ter uma réplica deste material didático, possa imprimi-lo em algum bureau equipado com uma impressora 3D, próximo de sua sede. Isto significaria entre outras coisas, importante economia nos custos de produção e frete, maior autonomia no acesso a recursos pedagógicos e democratização na divulgação da cultura artística brasileira.

Espera-se que este método de ação pedagógica signifique uma expansão da descrição da obra artística, de maneira que não seja reduzida à mera apresentação visual ou uma experiência tátil guiada por uma legenda preestabelecida, que determine a experiência apenas como uma relação burocrática e literal entre obra e texto. Para o caso das instituições de ensino, espera-se que o método possa auxiliar alunos e professores, videntes ou não, a compreender as sutilizas e nuances da fruição artística, descrevendo as obras para além dos manuais escolares e dos programas de ensino preestabelecidos. É importante para o método, a premissa de que a experiência artística implique compreensão da linguagem, construção de sentidos, ampliação do repertório e contato com o poético. Para o deficiente visual, que não possui de antemão um conhecimento da linguagem das artes plásticas, o método procura ser uma possibilidade no ensino de códigos de leitura e interpretação, para que possa, ele mesmo, adquirir conhecimento e criar formas de apreensão e compreensão da linguagem artística visual.

Ao mesmo tempo, espera-se a compreensão dos limites e possibilidades da percepção tátil e do alcance dessa metodologia de ensino das artes junto aos deficientes visuais, para que esse processo se estenda à outras obras e que constitua uma metodologia diferenciada de ensino das artes. Os resultados desse trabalho são fundamentais para o estabelecimento de parâmetros para o trabalho futuro com obras de grandes dimensões.

Espera-se também disponibilizar para escolas um acervo artístico que possa ser impresso e trabalhado pelos professores de artes em diferentes partes do país, tornando o acervo artístico disponível e presente no cotidiano dos alunos.

\section{Procedimentos Metodológicos Materiais e Técnicos}

A constituição de uma réplica obtida a partir da obra original, através de processos tecnológicos, implica nas seguintes etapas:

a. Sequência de fotografias da obra de arte abrangendo sua totalidade volumétrica.

b. Processamento estereofotogramétrico em ambiente computacional, para geração do modelo digital da obra original.

c. Edição do modelo digital.

d. Impressão 3D em tecnologia FDM dos modelos articulados e da réplica da obra de arte em tamanho original.

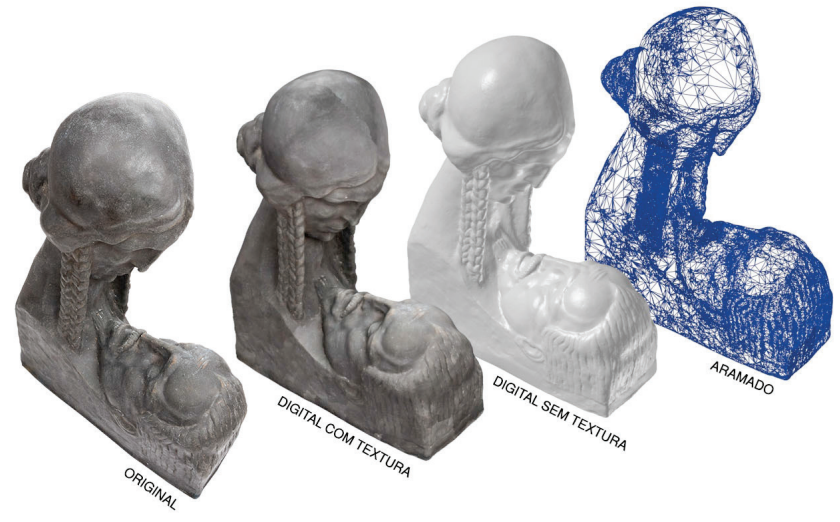

Figura 3: Processo de captura e modelagem.

\section{Conclusão}

A fruição de uma obra de arte visual por pessoas cegas, constitui-se por definição, em um dilema. A presunção comum, de que basta apresentar a este público réplicas ou miniaturas das obras de arte, não considera a limitação da inexistência de referentes capazes de estruturar uma compreensão mais ampla. Além disso, também não consideram subjetividades estilísticas comuns nas expressões artísticas, tal como ocorre nas abstrações.

Odesafiodeencontrar caminhos narrativos para a fruiçãoda obra artística, pode encontrar meios eficazes no uso de metáforas e na exploração de outros sentidos, para além da sensibilidade do toque pelas mãos. Recurso como as audiodescrições e mapas sonoros podem ser aliados preciosos, mas também podem não ser suficientes para darem conta da demanda. 
A resolução do problema parece estar situada entre compreender de que maneira os processos cognitivos humanos se alteram com a ausência da visão, e de que maneira pode-se retirar uma obra de arte de seu contexto original, e transformá-la de maneira que também sejam atendidas as particularidades do público não vidente.

As tecnologias integradas da fabricação digital, que utilizam entre outras, a estereofotogrametria e a impressão 3D, surgem como novos aliados dos arte educadores e dos gestores de políticas para a disseminação da cultura. A possibilidade de se obter uma cópia digital através de um método de escaneamento que utiliza apenas uma câmera fotográfica como recurso, abre a possibilidade de compartilhamento online dos dados, bem como possibilita a edição, através de softwares de modelagem, de maneira que o modelo escaneado possa ser transformado e adaptado à narrativa pedagógica.

A utilização da impressora 3D de tecnologia FDM (filamento), que começa a tornar-se acessível com a diminuição dos custos relativos à aquisição dos equipamentos e de sua operação, amplia as possibilidades de materialização dos protótipos táteis, sem limitação no que se refere à quantidade de cópias, e sua distribuição às pessoas e instituições interessadas.

Espera-se que a ação combinada entre uma crescente compreensão dos dilemas relacionados à arte educação inclusiva, e a ampliação dos recursos tecnológicos de prototipagem e compartilhamento das informações, possam aproximar o público em geral, e em especial os não videntes, do universo amplo das artes.

\section{Agradecimentos}

Agradecemos o apoio do Museu Casa Guilherme de Almeida /São Paulo através do seu diretor Marcelo Tápia e do museólogo Ivanei da Silva, cuja generosidade e disposição tornaram esse trabalho possível

\section{Referências}

BRASIL. Decreto no. 5.296, de 2 de dezembro de 2004. Regulamenta as leis no. 10.048, de 8 de novembro de 2000, que dá prioridade de atendimento `as pessoas que especifica, $\mathrm{e}$ no. 10.098 , de 19 de dezembro de 2000, que estabelece normas gerais e critérios básicos para a promoção de acessibilidade das pessoas portadoras de deficiência ou com mobilidade reduzida, e dá outras providências. Diário Oficial da União. Brasília, 2004.

Parâmetros curriculares Nacionais: Adaptações Curriculares. Brasília, 1998. Disponível em www. educacaoonline.pro.br/adaptacoes_curriculares,asp

CAMARGO, Eder Pires. Saberes docentes para a inclusão do aluno com deficiência visual em aulas de Física. São Paulo: Unesp, 2012

CARVALHO, E.N.S.; MONTE, F.R.F. A educação inclusiva de portadores de deficiências em escolas públicas do DF.Temas em Educação Especial III. São Paulo: Editora Universidade de São Carlos,1995

DIMBLERY, R. ; BURTON, G. Mais do que palavras: uma introdução à teoria da comunicação. 4.ed.São Paulo: Cortez, 1990

FRANÇA, V.V. O objeto da comunicação: a comunicação como objeto. In: HOHLFELDT, A. et. al. (Org.) Teoria da comunicação: conceitos, escolas e tendências 5, ed. Petrópolis: Vozes, 2005 MASINI, E,F.S. Impasses sobre o conhecer e o ver. In: O perceber e o relacionar-se do deficiente visual: orientando professores especializados. Brasília: Corde, 1994

MITTLER, P. Educação inclusiva: contextos sociais. São Paulo: Artmed, 2003

PARRA, N.; PARRA, I. C.C. Técnicas audiovisuais de educação 5.ed. São Paulo: Pioneira, 1985

TARDIF, M. Saberes docentes e formação profissional. Petrópolis: Vozes, 2004

VIGOTSKI, L.S. Fundamentos da defectologia: el niño ciego. In: Problemas especiales da defectologia. Havana: Editorial Pueblo y Educación, 1997.

ZABALA, A.A. A prática educativa: como ensinar. Porto Alegre: Artmed, 1998

BONSIEPE, Guy. Do material ao digital. São Paulo: Bluncher Editora, 2015

MCCULLOUGH, Malcolm. Abstracting Craft: The Practiced Digital Hand, Massachussets: MIT Press, 1998.

FLUSSER, Vilém. O mundo codificado. São Paulo: CosacNaify, 2007

BRITO, Jorge; COELHO, Luiz. Fotogrametria digital. 1. ed. Rio de Janeiro: IME - Instituto Militar de Engenharia, 2009. 